AUTHOR:

Manfred A. Hellberg ${ }^{1}$

\section{AFFILIATION:}

${ }^{1}$ School of Chemistry and

Physics, University of KwaZulu-

Natal, Durban, South Africa

\section{CORRESPONDENCE TO:} Manfred Hellberg

\section{EMAIL:}

hellberg@ukzn.ac.za

\section{HOW TO CITE:}

Hellberg MA. Professor ADM (David) Walker: World-class physicist (1937-2018). S Afr J Sci. 2018;114(11/12), Art. \#a0298, 2 pages. http://dx.doi. org/10.17159/sajs.2018/a0298

\section{PUBLISHED:}

27 November 2018

\title{
Professor ADM (David) Walker: World-class physicist (1937-2018)
}

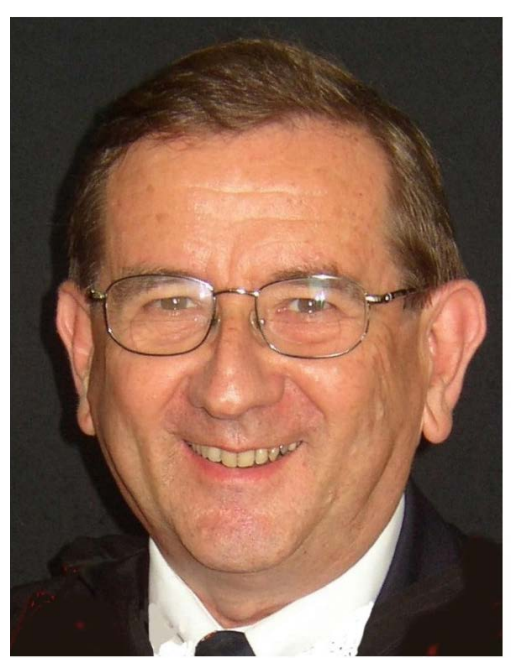

Professor ADM (David) Walker, one of South Africa's most distinguished scientists, died on 17 September 2018, aged 80. He was Professor of Theoretical Physics at the then University of Natal from 1972 (and Senior Professor from 1989) until he retired in 2002. After retirement, he continued as an active researcher until the end, as Emeritus Professor and Senior Research Associate of the now University of KwaZulu-Natal. After undergoing surgery in June, he unfortunately never really recovered. He will be missed by many, including his colleagues and students, as well as the wider space science community, both nationally and internationally.

After matriculating at Umtata High School, Walker went to Rhodes University, where he came under the influence of two top scientists: Professors JA Gledhill (Physics) and D Burnett (Applied Mathematics). Burnett's work on the kinetic theory of non-uniform gases, published in the 1930s in Proceedings of the London Mathematical Society, is still cited eight decades later. And Jack Gledhill, a polymath, is regarded by many as being the father of space physics in South Africa.

After his BSc (Hons) (1959) he was employed as a Junior Lecturer and Lecturer at Rhodes (1960-1962), while doing an MSc on 'Solar eclipses and the ionosphere' with Gledhill. This work led to a joint publication, as well as a single-author paper in Nature. Awarded a Shell Postgraduate Scholarship to St. John's College, Cambridge, he did research under Budden (FRS, 1966) at the Cavendish Laboratory. His PhD thesis (1966) entitled 'Radio waves in the ionosphere and exosphere' led to three further single-author papers in leading journals, on the theory of radio propagation. After returning to Rhodes he was promoted to Senior Lecturer, before his move to Durban in 1972.

David Walker was recognised internationally as a world leader in space physics. After his early research on radio propagation and ray tracing, particularly of very-low frequency radio waves, much of his later work centred on ultra-low frequency pulsations of the earth's magnetic field with periods of the order of seconds, hydromagnetic waves in the magnetosphere (the region of space affected by the geomagnetic field), and related magnetospheric and ionospheric phenomena. In addition to carrying out sophisticated mathematical-computational calculations, he was also involved in the analysis and interpretation of both ground-based and satellite observations of the behaviour of the ionised gas (plasma) of geospace.

In 1977-1978 he spent a sabbatical as an Alexander von Humboldt Fellow at the Max Planck Institut für Aeronomie (Lindau-Katlenburg, Germany), where he joined Ray Greenwald. The 1979 paper by Walker, Greenwald, et al. is a classic and has been cited 260 times. Applying Walker's theoretical insight and understanding to the analysis of data from STARE (Scandinavian Twin Auroral Radar Experiment), a concept developed by Greenwald, the paper provided complete understanding of the origin of continuous long-period geomagnetic pulsations (Pc5) arising from hydromagnetic field line resonances. It also showed that STARE-type radar set-ups can provide a powerful new diagnostic technique for geomagnetic pulsation phenomena and hence deepen our understanding of the magnetosphere. In due course, a global network of such dual auroral radars, SuperDARN, was set up.

Walker was a co-initiator of and a Principal Investigator from 1993 to 2002 on the international project known as SHARE (Southern Hemisphere Auroral Radar Experiment) involving dual radars at the South African Antarctic base (SANAE) and the British base (Halley Bay). More generally, he was a highly regarded member of the international SuperDARN community.

When the Foundation for Research Development (FRD), forerunner of the National Research Foundation, introduced international peer evaluation in 1984, he was one of the first group of about a dozen scientists across all disciplines to earn an A-rating (leading international scientist). Despite university, national and international management roles, he retained his A-rating throughout successive re-evaluations to his retirement in 2002, after which it dropped to a B-rating (internationally acclaimed). He was also the first Chair of the FRD Physics Evaluation Committee (1984-1990), and a member of both the Main Awards Committee and the FRD Collegium.

Walker received many accolades. In 1998, the South African Institute of Physics (SAIP) awarded him its highest honour, the biennial SAIP de Beers Gold Medal, and he was elected a Fellow of SAIP when that honour was introduced in 2012. He was also elected a Fellow of the Institute of Physics (London) (1976-1985), the Royal Society of South Africa (1988-) and the University of Natal/KwaZulu-Natal (1989-), and was a Founder Member of the Academy of Science of South Africa (1994-).

For many decades, he played an important role in a range of national committees for radio science, space science and Antarctic research, and represented South Africa internationally on the parent bodies, with acronyms such as URSI, COSPAR, SCOSTEP and SCAR. Amongst others, he served on the Advisory Committee of the Hermanus Magnetic Observatory, chaired the National Committee for the International Polar Year (2006-2008), was on the International Review Panel for the National Space Programme led by SANSA (2012), and was a SANSA Board member in 
2013-2014. After his retirement, he served on the NASSP (National Astrophysics and Space Science Programme) Steering Committee and taught a NASSP master's module on 'Magnetohydrodynamic waves in space' for several years. He was also on the Editorial Advisory Boards of both the South African Journal of Physics and the South African Journal of Antarctic Research.

Walker interacted with many other leaders in the field. Apart from his sabbatical in Germany, his sabbatical and research visits included a year at Cambridge University, three visits of 3-9 months at Johns Hopkins University (Maryland, USA) and 3 months at the British Antarctic Survey (Cambridge, UK). He also gave a 6-week postgraduate course of his choice as Guest Professor at KU Leuven (Belgium).

Internationally, his research and his views were highly regarded. Walker was elected Vice-President of the ICSU Scientific Committee for Antarctic Research (SCAR) in 1998-2002 and Chair of the Solar Terrestrial and Astrophysical Research Working Group of SCAR (1994-2000). He also served on the Editorial Advisory Board of Planetary and Space Science (1982-1992), and in 1999 received an Editor's Award for excellence in refereeing from the prime US journal, Journal of Geophysical Research Space Physics, before being appointed an Associate Editor (2000-2002).

Walker published 85 peer-reviewed research articles, many of them singly authored, and his work has been cited more than 3000 times. His latest three papers appeared in 2016, but ongoing projects should lead to further publications. In addition, he presented 79 papers at international and 56 at national conferences. Unusually, for a physicist, he also wrote two major research books: Plasma Waves in the Magnetosphere (Springer, 1993) and Magnetohydrodynamic Waves in Geospace: The Theory of ULF Waves and their Interaction with Energetic Particles in the Solar-Terrestrial Environment (Institute of Physics Press, 2004). He graduated $8 \mathrm{PhD}$ and $10 \mathrm{MSc}$ students, and a final student submitted his master's thesis recently.

Walker was a consummate all-round academic. Apart from being a world-class researcher, he took teaching seriously. When he joined the University of Natal, he brought a fresh look to our teaching and had a significant impact, for instance, in the development of lecture demonstrations and in supporting teaching experiments. His lectures were known for their clarity, his depth of understanding of physics and his well-planned notes.
During his career, he filled various management roles at the University of Natal, including Head of the Department of Physics for 16 years, Dean of Science, part-time Pro-Vice Principal (Information Systems) for 2 years, Acting Vice-Principal (for three short spells), and member of Council and numerous committees of Senate. He even chaired the Trustees of the University Retirement Fund. After retiring, he held part-time posts as Pro-Vice-Chancellor (Research) (2003-2004) and as Director of Special Programmes in the UKZN Research Office (2005-2006). These involved a variety of projects, including, for instance, merging 3 independent and 16 branch libraries, and setting up a Research Ethics Guide and protocols for the new, merged institution.

His academic leadership style was characterised by his friendliness, his analytical, incisive mind, his integrity and fairness, his ability to delegate and his decisiveness. As a retired colleague wrote: 'It was a pleasure to be a member of the Physics Department he led so superbly - many happy memories!'

Walker had a way with words. The numerous documents that he prepared in his management roles were extremely well written, analytical and to the point. He was also an excellent speaker, whether as a debater in Senate, or as an entertaining after-dinner speaker. He was very well read, and that attribute was invariably reflected in his writing and his speeches.

After completing his second research monograph, Walker embarked on serious historical research, scouring museums and archives, following the story of his forebears, who were 1820 Settlers. This led to a 492page book entitled Pawns in a Larger Game: Life on the Eastern Cape Frontier in 2013.

He enjoyed listening to classical music (he was a regular at the KZNPO concerts for many years), gardening and watercolour painting. At one stage he took up long-distance running, and twice qualified for the Comrades Marathon, but to his regret did not finish.

During his Cambridge days, he met Carol Glencross, a Scottish statistician, and they married in 1967. Carol was very supportive of him throughout his career, and his family played an important part in his life. Their three children and six grandchildren now live in New York, Cape Town and Glasgow. Heartfelt condolences go to Carol and the family at this sad time. 